\title{
EVALUATION OF TWO DIFFERENT MATERIALS FOR PRE-ENDODONTIC RESTORATION OF BADLY DESTRUCTED TEETH Hamed $\mathrm{S}^{1}{ }_{B D S}$, Zaazou $\mathrm{A}^{2} P h D$, and Leheta $\mathrm{N}^{3} P h D$
}

\begin{abstract}
:
Introduction: Pulpal and periradicular diseases develop when microorganisms and/or their by-products contaminate these tissues. Therefore, the major goal of endodontic restoration is to prevent the penetration of microorganisms into the coronal pulpal space and root canal system.

Objectives: To evaluate and compare the sealing ability of two intermediate temporary filling materials in badly destructed teeth reinforced with stainless steel bands and to evaluate the adaptation of these materials upon application of clamps and rubber dam material.

Materials and methods: 65 mature maxillary premolar teeth were used in this study. This study was divided in two parts. Part I: evaluation of coronal leakage by glucose penetration model and spectrophotometer. Teeth were randomly divided into two experimental groups ( $\mathrm{n}=10$ ) and a control group $(\mathrm{n}=15)$. Access cavities and stimulation of loss of tooth structure were done. Instrumentation till apical size \# 35 and reinforcement with stainless steel bands were done. Group I: teeth were filled with Cavit-G (3M ESPE, Seefeld, Germany); Group II: teeth were filled with CLIP (Voco, Cuxhaven, Germany); Group III: used as positive and negative control group. Measurement of coronal leakage was performed at the 3rd, 7th and 15th day. Part II: evaluation of adaptation of coronal restoration by using $2.5 x$ magnifying loupes and USPHS criteria, grouping was done as before but ten teeth were used as positive controls.

Results: Part I; CLIP (group II) showed the least glucose leakage with median change of leakage (1052.45) mg/dl followed by Cavit-G (Group I) with median change of $(2828.55) \mathrm{mg} / \mathrm{dl}$. The difference was statistically significant $(\mathrm{P}=0.001)$. In part II; results were statistically significant $(\mathrm{p}=0.001)$, where the CLIP group showed better adaptation than Cavit-G group.

Conclusions: CLIP seals against marginal leakage better than Cavit-G. CLIP provides better adaptation than Cavit-G on application of clamps and rubber dam.

Keywords: Endodontics, temporary filling materials, coronal leakage, Cavit-G, CLIP.

1- Bachelor of Dentistry, Faculty of Dentistry, Alexandria University, Alexandria, Egypt

2- Assistant Professor of Endodontics, Faculty of Dentistry, Alexandria University, Alexandria, Egypt

3- Lecturer of Endodontics, Faculty of Dentistry, Alexandria University, Alexandria, Egypt
\end{abstract}

\section{INTRODUCTION}

Loss of integrity of coronal tooth structure and invasion of microorganisms into dentin and pulp space play a very important role in pulpal and periradicular diseases. Coronal microleakage appears to be of equal or greater clinical relevance as a factor in endodontic success or failure than apical leakage due to risk of recontamination (1).

Teeth with root canal fillings should immediately receive definitive restorations, as coronal microleakage could occur in a few days (2).

The coronal filling material is considered to be effective when it is able to fulfill certain properties, including good sealing of tooth margins, lack of porosity and dimensional changes to hot and cold temperatures, good abrasion and compression resistance, easy insertion and removal, compatibility with intracanal medicaments, and good esthetic appearance (3).

The pretreatment of broken-down teeth with a stainless steel band helps in improvement of isolation during endodontic treatment. Its use transforms a complex endodontic access cavity preparation into a simple class I cavity, thus assisting the in-between visits sealing quality of some temporary filling materials (4).

Cavit (3M ESPE, Seefeld, Germany) is one of the most commonly used temporary restorations among endodontists for both anterior and posterior teeth. However, Cavit is not esthetic and it is not durable against the force of mastication especially in complex cavities as it leads to extensive cracks and extrusion from the tooth preparations (5).

In an effort to improve the sealing and mechanical properties of temporary restorations, different materials have become available in the market. Recently, a light cure composite resin (Clip; Voco, Cuxhaven, Germany) was introduced as a temporary restorative material in endodontics (6). It contains hydroxyethylmethacrylate, butylhydroxytoluene, acrylate-ester, and polymers. The application of clamps and rubber dam could affect the adaptation of the core materials which can be easily cracked and lose their adaptation under the force applied from the clamps throughout the endodontic treatment.

There are controversies regarding the test methods and tracer substances used to detect microleakage and compare the relative sealing performance achieved with different materials $(7,8)$.

The glucose leakage test was first introduced in 2005 to evaluate endodontic leakage. Glucose has been proposed as a tracer substance for evaluating endodontic leakage because of its small sensitive molecular size (9). The amount of glucose leakage is quantified with spectrophotometry.

The aim of the present in vitro study was to evaluate and compare the sealing ability of two intermediate temporary 
filling materials in badly destructed teeth reinforced with stainless steel bands using a glucose model test and spectrophotometry. Furthermore, the adaptation of the temporary filling materials on application of clamps and rubber dam was done by macroscopic examination using magnifying loupes. The null hypothesis was that, the CLIP temporary filling material was as efficient as Cavit-G temporary filling material in sealing ability.

\section{MATERIALS AND METHODS}

Sixty-five mature maxillary premolar teeth with mature apices were used in this study. Teeth were cleaned from soft tissue or debris using a sharp scalpel, then teeth were stored in isotonic saline solution at $100 \%$ humidity and $37^{\circ} \mathrm{C}$ till use.

\section{Part I of the study:}

Sample preparation: Thirty-five teeth were randomly divided into two experimental groups of 10 teeth each according to the temporary material used for restoration, and a control group of 10 teeth for positive control group and 5 teeth for negative control group. Access cavities were done by using a round diamond bur mounted on a high speed hand piece followed by a non-cutting end bur as the Endo- $Z$ bur (Dentsply Maillefer, Ballaigues, Switzerland) to smooth and flare the walls of the access cavity. Stimulation of loss of tooth structure was done by preparing mesio-occlusodistal (MOD) intracoronal cavities. The palatal cusps were removed coronal to the cemento-enamel junction (CEJ) by using a fissure diamond bur mounted on a high speed handpiece with water cooling.

A periodontal probe was used to measure the depth of the access cavities; occlusal adjustment was performed so that the depth of the access cavities was $5 \mathrm{~mm}$ corresponding to the final thickness of the temporary filling material. Periapical patency was done then a size $15 \mathrm{~K}$-file (Dentsply Maillefer, Ballaigues, Switzerland) was inserted into the root canal until the tip became visible at the apical foramen; then $1 \mathrm{~mm}$ was subtracted and taken as the working length. After accurate determination of working length, all root canals were enlarged in a step-back technique reaching an apical preparation size 35. During instrumentation, the canals were flushed with 3\% NaOCL as an irrigating solution using disposable syringes and 30gauge needles (Ultradent Product, Inc., South Jordan, Utah, USA).

After completion of instrumentation the root canals were flushed for 1 minute with $2.0 \mathrm{ml}$ of $17 \%$ EDTA solution, then washed with $2.0 \mathrm{ml}$ of $3 \% \mathrm{NaOCl}$ solution followed by copious rinsing with $5.0 \mathrm{ml}$ saline. Finally the canals were dried with paper points. A dry cotton pellet was placed in the pulp chamber.

The best fitting premolar stainless steel band was selected for each tooth and tested for size and fit. Ketac Cem easy mix (3M ESPE, Seefeld, Germany) was used as the luting agent to cement the band. Glass ionomer cement (GIC) powder and liquid of equal ratio was mixed according to manufacturer's instructions then applied to the stainless steel bands and seated on the teeth. Excess material was removed and GIC was left to set.
The temporary filling materials were packed according to manufacturer's instruction by the same operator at the site of access opening according to the grouping:

In group I, a readymade paste of Cavit-G was applied with a suitable instrument to fill the required quantity into the wet cavity of the experimental teeth. Excess materials were removed and left to set. The hardening process started after a few minutes.

In group II, teeth were rinsed and dried, CLIP was applied to the cavities with a suitable instrument (spatula or plastic filling instrument), contoured, excess material was removed and the material light cured for 40 seconds using LED light curing device (Woodpecker, LED, China).

After that, teeth were thermo-cycled between $5^{\circ} \mathrm{C}$ and $55^{\circ} \mathrm{C}$ for 300 cycles, for 10 seconds at each temperature (10). The external surfaces of each tooth from the experimental groups were covered with two layers of nail varnish except for the apical $2 \mathrm{~mm}$.

Preparation of the glucose penetration model: The coronal part of the tooth was attached to the end of an Eppendorf vial. A hole was created in the cap of the eppendorf vial, through which a glass tube of at least $15 \mathrm{~cm}$ long was connected. The assembly was placed in a sterile $5 \mathrm{ml}$ glass bottle with a rubber cap. Leakages at all connections were eliminated by use of cyanoacrylate glue and sticky wax. The tracer in the present study was $(1 \mathrm{~mol} / \mathrm{L}, \mathrm{pH} 7.0)$ glucose solution, with density of $1.09 \times 103 \mathrm{~g} / \mathrm{L}$ and viscosity of $1.18 \times 10-3$ (pas.) at $37^{\circ} \mathrm{C}$. About $5 \mathrm{ml}$ glucose solution containing $0.2 \%$ sodium azide $(\mathrm{NaN} 3)$, was injected into the Eppendorf vial from the glass tube until the top of the solution was $14 \mathrm{~cm}$ higher than the top of the root, creating a hydrostatic pressure of $1.5 \mathrm{KPa}$. Glucose that leaks through the tooth crown and root canal was collected in the glass bottle containing $1 \mathrm{~mL}$ of $0.2 \%$ sodium azide. (fig. 1)

The NaN3 was used here to inhibit the proliferation of microorganisms that might decompose glucose. The seal at

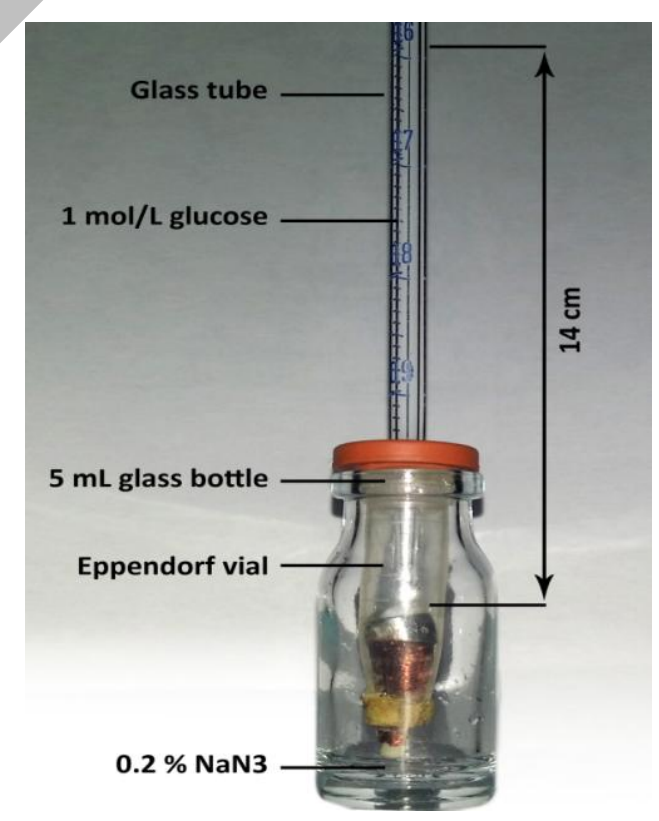

Fig. 1: Glucose leakage model. 
all junctions were checked by connecting the end of the glass tube to compressed air. Any bubbles would indicate leakage of the assembly. So in this case sticky wax was used to eliminate this leak. The model was then transferred to an incubator that provided $100 \%$ humidity and $37^{\circ} \mathrm{C}$ temperature for the duration of observation periods (11).

Spectrophotometric measurement of microleakage: Measurement was performed at the 3rd, 7th and after 15 days. A spectrophotometer was used to analyze the amount of glucose leaked in the glass bottle (12). A total of $10 \mu \mathrm{L}$ of solution was drawn from the glass bottle using a micropipette and replaced with same amount of sodium azide solution to maintain a constant volume of $1 \mathrm{ml}$. Each sample from each glass bottle was placed in an eppendorf vial. Fifty microns of glucose marker was added to each sample using a micropipette. This mixture was left for a few seconds and any change in color was examined in which glucose oxidase catalysis the oxidation of glucose to gluconic acid. The formed hydrogen peroxide was detected by a chromogenic oxygen acceptor in the presence of peroxidase. The intensity of the color formed was proportional to the glucose concentration in the samples so if the mixture turned pink this indicates the presence of glucose. The samples were then analyzed using a UV spectrophotometer at $500 \mathrm{~nm}$ wave length. The exact amount of leaked glucose appeared on the screen in $\mathrm{mg} / \mathrm{dl}$ (13).

\section{Part II of the study:}

Thirty teeth were randomly divided into two experimental groups of 10 teeth each, and a control group of 10 teeth used as positive controls. After temporary filling materials were applied in the experimental teeth, teeth were clamped using hygienic $®$ bicuspid winged clamp \#2A then rubber dam were applied. Standard access cavities were done through the temporary filling materials in each group. The applied clamp was left for 30 minutes then the cavities were redressed with the same materials followed by thermocycling between $5^{\circ} \mathrm{C}$ and $55^{\circ} \mathrm{C}$ for 300 cycles, for 10 seconds at each temperature. The adaptation between the temporary filling materials and stainless steel band was examined by macroscopic examination using $2.5 \mathrm{X}$ magnifying loupes (figures 2 and 3 ).

Evaluation of the adaptation: All teeth were evaluated for adaptation using modified United States public health service (USPHS) criteria (14). Two evaluators who were not involved in the placement of the fillings and unaware of the materials used performed the evaluation in this double-blind study. When disagreement arose during evaluation, the evaluators had to reach a consensus. All evaluations were carried out under a dental operating light, using dental explorers and magnifying loupes with a power of $2.5 \mathrm{X}$. A new explorer was used for the evaluation of each tooth. Based on USPHS criteria, adaptations were rated as alpha, bravo and Charlie according to the following characteristics; Alpha: Closely adapted, no visible crevice (explorer does not catch), Bravo: Visible crevice, explorer will penetrate and Charlie: The temporary filling is fractured.

All statistical analysis was done using two tailed tests and alpha error of 0.05 . The results were statistically analyzed using Kruskal Wallis and Monte Carlo tests.

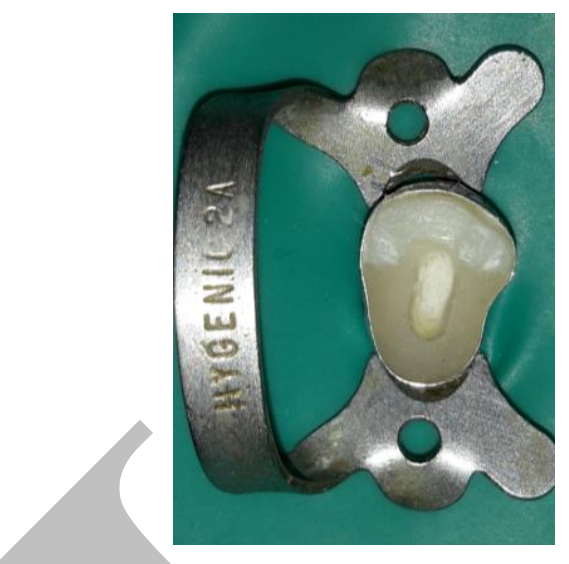

Fig. 2: CLIP adaptation.

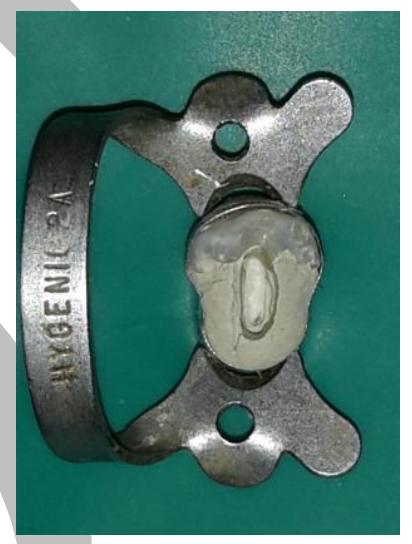

Fig. 3: Cavit-G adaptation.

\section{RESULTS}

Part I results: The mean and median leakages of experimental groups at different time intervals are shown in table 1.

Table 1: Descriptive comparison of leakage between the experimental groups at different time intervals.

\begin{tabular}{|c|c|c|c|c|c|}
\hline \multirow{2}{*}{ Group } & \multirow{2}{*}{ Leakage (mg/dl) } & \multicolumn{2}{|c|}{ Day } & \multirow[b]{2}{*}{$15^{\text {th }}$ day } & \multirow{2}{*}{$X^{2}(\mathbf{P})$} \\
\hline & & $3^{\text {rd day }}$ & $7^{\text {th }}$ day & & \\
\hline \multirow{5}{*}{$\begin{array}{l}\text { AVIT-G } \\
\text { group I) }\end{array}$} & Minimum & $\overline{15.6}$ & 183.1 & 577.0 & \multirow{5}{*}{$18.2(0.001)^{*}$} \\
\hline & Maximum & 283.1 & 1900.9 & 4128.0 & \\
\hline & Mean & 96.3 & 1007.3 & 2673.1 & \\
\hline & SD & 82.8 & 565.1 & 1234.2 & \\
\hline & Median & $80.5^{d}$ & 1079.2 & $3000.5^{\mathrm{d}}$ & \\
\hline \multirow{5}{*}{$\begin{array}{r}\text { CLIP } \\
\text { group II) }\end{array}$} & Minimum & 12.9 & 88.3 & 755.0 & \multirow{5}{*}{$15.6(0.001)^{*}$} \\
\hline & Maximum & 161.7 & 600.2 & 1800.0 & \\
\hline & Mean & 53.6 & 235.0 & 1138.0 & \\
\hline & SD & 52.6 & 192.7 & 285.6 & \\
\hline & & $32.6^{\mathrm{d}}$ & 147.3 & $1095.0^{\mathrm{d}}$ & \\
\hline \multicolumn{2}{|c|}{$\mathbf{H}(\mathbf{P})$} & $5(0.001)^{*}$ & $1.3(0.001)^{*}$ & $9(0.001)^{*}$ & \\
\hline
\end{tabular}

$\mathrm{X} 2$ : Friedman test for repeated measures

$\mathrm{H}$ : Kruskal-Wallis test for independent groups

$* \mathrm{P}<0.05$ (significant) d: significantly different of others

Excessive amount of glucose leakage was observed in the positive control group $(\mathrm{n}=10)$, and no leakage was detected in the negative control group $(n=5)$, which 
confirmed the functioning and reliability of the experimental model. It was noted that there was a tendency for increased coronal leakage from the 3 rd day to the 15 th day for all studied groups.

When comparing the leakage throughout the study period, results showed a statistically significant difference between all studied groups $(\mathrm{p}=0.001)$. CLIP (group II) showed the least glucose leakage among all studied group with median leakage change of $(1052.45) \mathrm{mg} / \mathrm{dl}$ followed by Cavit-G (group I) with median change of $(2828.55) \mathrm{mg} / \mathrm{dl}$, and positive control group with the highest leakage with median change of (3942) $\mathrm{mg} / \mathrm{dl}$ (table 2).

Table 2: Median change of leakage of different studied groups throughout the study period.

\begin{tabular}{|c|rrr|r||}
\hline \multirow{3}{*}{ Group } & \multicolumn{3}{|c|}{ Change } & H (P) \\
& Minimum & Maximum & Median & \\
\cline { 2 - 5 } & 638.7 & 1638.3 & 1052.45 & \\
\hline \hline CLIP & 457.9 & 4027.8 & 2828.55 & $12.5(0.001)^{*}$ \\
CAVIT-G & 0 & 5635 & 3942 & \\
Control & & & & \\
\hline
\end{tabular}

$\mathrm{H}$ : Kruskal-Wallis test for independent groups

$* \mathrm{P}<0.05$ (significant)

Part II results: When comparing the adaptation, it was found that CLIP (group II) showed a statistically significant difference from Cavit-G (group I) $(\mathrm{p}=0.001)$. In the CLIP group, nine out of ten teeth gave an Alpha score with $90 \%$, $10 \%$ for bravo score and $0 \%$ for Charlie score. While in Cavit-G group, eight out of ten teeth give bravo score with $80 \%, 20 \%$ for Charlie score and $0 \%$ for alpha score (table $3)$.

Table 3: Adaptation evaluation of CLIP and Cavit-G.

\begin{tabular}{|c|c|c|c|c|c|}
\hline \multirow{3}{*}{$\begin{array}{r}\text { Adaptation of } \\
\text { temporary } \\
\text { filling materials }\end{array}$} & \multicolumn{2}{|c|}{ Group } & & & \multirow{3}{*}{ MCP } \\
\hline & \multicolumn{2}{|c|}{ CLIP } & \multicolumn{2}{|c|}{ CAVIT-G } & \\
\hline & No & $\%$ & No & $\%$ & \\
\hline Alpha & 9 & 90.0 & 0 & 0.0 & \\
\hline Bravo & 1 & 10.0 & 8 & 80.0 & $0.001 *$ \\
\hline Charlie & 0 & 0.0 & 2 & 20.0 & \\
\hline
\end{tabular}

MCP: Mont Carlo exact probability

$* \mathrm{P}<0.05$ (significant)

According to modified USPHS criteria, the CLIP group showed better adaptation than the Cavit-G group.

\section{DISCUSSION}

Temporary filling materials which prevent the entry of saliva and microorganisms should be used (15). Studies demonstrated that in the absence of an adequate coronal temporary seal, contamination of the root canal system could occur in less than three days (16). Several studies have shown that these materials are incapable of preventing coronal marginal leakage, leading to root canal contamination and inducing the appearance of periapical lesions (17). Temporary sealing materials must not be kept in the root canals for a long period of time due to the risk of contamination (18).

In the present study, a light curing temporary filling material (CLIP) was compared with a commonly used temporary filling material (Cavit-G) to evaluate the coronal microleakage and adaptation of each material.

Cavit-G is an autopolymerized, moisture-initiated, premixed temporary restorative material that contains zinc oxide, calcium sulfate, glycol acetate, polyvinylacetate resins, polyvinyl chloride acetate, tri-ethanolamine and pigments. Cavit-G and Cavit-W are varieties of Cavit that differ in the content of resin and their resulting hardness and setting. The hardness and dimensional stability of Cavit is higher than that of Cavit-W which in turn is higher than that of Cavit-G. It is a hygroscopic material which possesses a high coefficient of linear expansion, resulting from water sorption which permits the material to adapt to dentin walls. It is widely used between appointments during routine endodontic therapy, probably because of its practical "ready to use" condition (19).

On the other hand, CLIP is a resin based light curing temporary filling material similar to fermit (Vivadent, France), TERM (DENTSPLY-Caulk) and spacer (Vericom) which has shown good sealing ability in previous studies(20,21). CLIP is composed of BIS-GMA, silicon dioxide, groups of dimethacrylate and organic filler particles. CLIP is a durable material with tight margins, it is ready to use, easy to place, and easy to remove in one piece with no damage to preparation boundaries (21). It does not contain eugenol does not have a negative effect on composite bond strength (22). According to the manufacturer, polymerization shrinkage is minimal and it does not influence sealing.

In the present study, extracted intact maxillary premolars teeth were used, as most fractures occur in the palatal cusps of maxillary premolars which are considered the functional cusps (23). Teeth selected for the current study were of average length and width. Any discrepancy in length was adjusted by occlusal adjustment and the width was adjusted by using a digital caliber. The depth of access cavities of all teeth were measured by using a periodontal probe. A total thickness of five $\mathrm{mm}$ in depth was used in this study in order to comply with the recommendations of Webber et al. (24), who found that a $3.5 \mathrm{~mm}$ thickness of restorative material was the minimum thickness necessary to prevent microleakage. Periapical patency was done to insure that no blockage occurred at the periapical foramen during instrumentation.

For reinforcement, orthodontic stainless steel bands were used, as it was found by Jensen et al (4) and Heffer (25) that the most important function of stainless steel bands used in endodontic treatment is to help in retaining interim 
restorations during phases of endodontic treatment. Furthermore, stainless steel bands reduced the cuspal flexure by one-half compared to teeth without bands and doubled the fracture strength (26).

Thermocycling procedures attempt to simulate temperature changes that take place in-vivo. Temperature fluctuations can adversely affect the marginal seal of a dental material. To test this factor, thermocycling was incorporated into this study design. The temperature range used in thermocycling $\left(5^{\circ} \mathrm{C}\right.$ and $\left.55^{\circ} \mathrm{C}\right)$, corresponds to the extremes of temperatures experienced in the oral environment (27).

A variety of experimental models may be used to measure the coronal leakage; they include dye penetration, fluid transport, bacterial penetration and radioisotope. In the present study, glucose penetration was used (9). Benefits of the glucose penetration model are attributed to the tracer, the possibility of quantitative measurements, reproducibility, and sensitivity (9). Glucose is used as a tracer because it is hydrophilic, has a molecular weight lower than bacteria (MW=180 Da) and serves as a nutrient for bacteria (9). In the present study the level of glucose penetration was measured at 3rd, 7th, and 15th days, representing time intervals for endodontic treatment or when permanent restoration is carried out after root canal treatment. Different observations such as one week, two weeks, or longer, have been used for the evaluation because leakage increases by time regardless of the technique (28).

Under the condition of the present study, the positive control group showed the highest glucose leakage, while none of the five teeth used in the negative control group showed any leakage which confirmed the functioning and reliability of the experimental model.

In the experimental groups, group I (Cavit-G) showed the highest leakage. These findings may be attributed to the fact that expansion of hygroscopic restorative materials leads to poor adaptation at the interface of restorative material and cavity walls (24), also Cavit showed body leakage even when allowed to set in water before immersion in dye this may be due to sorption property of this material (29). The present results confirmed the findings reported by Anderson et al (20) that Cavit restorations were deemed clinically unacceptable in complex endodontic access preparations. This may be attributed to extensive cracks, expansion and extrusion from the tooth preparations. Furthermore, Beach et al (30) showed that Cavit hardness, wear resistance, slow-setting reaction and deterioration with time are key disadvantages. For these reasons, Cavit can be recommended for short-term temporization in small cavities without contact with the antagonizing tooth. In addition, Ludlow (31) found that Cavit-G demonstrated significantly higher leakage after thermocycling. On the contrary, Gilles et al (32) and (Oppenheimer \& Rosenberg) (33) found that thermocycling did not adversely affect Cavit products, indicating good dimensional stability, which could be attributed to linear expansion.

According to group II results, CLIP showed the least glucose leakage. The good sealing properties of CLIP could be attributed to minimal shrinkage and the mode of insertion of this material which eliminates the possible inclusion of gaps within the body of the material or at the margins. In addition to the setting reaction which was initiated by exposure to a visible light source. This property enables CLIP to be placed and set, offering no postoperative delays to achieve maximum function. Moreover, Uranga et al (34) found that composite resin based temporary filling materials provided a better seal against leakage after thermocycling when compared to Cavit. Our results are in line with Odabas et al (35) who found that CLIP exhibited the best sealing ability amongst the five tested materials (IRM, Adhesor, Cavit-G, Coltosol and CLIP). Also Tulunoglu et al (36) found that CLIP provided a better seal against microleakage at amalgam and especially composite interfaces, this material also provided a better seal against microleakage at the tooth tissue interface. On the other hand Ciftci et al (21) found that CLIP seals against marginal leakage as effectively as Cavit-G when used as a temporary filling. The disparity between this result and our findings may be attributed to the difference in experimental methods as they used dye penetration test for the evaluation while the present study used glucose penetration model which is more sensitive.

Numerous investigations on microleakage have obtained varying results using Cavit. According to Lim (37), the contradictory reports on the microleakage of Cavit may be due to the differences related to the duration and methods of evaluating microleakage in the different studies.

The lack of saliva and masticatory forces may create inaccuracies in in-vitro leakage studies. Qvist (38) found that occlusal loading had significant effect on the marginal leakage of resin restoration.

In part II of the study, application of clamps after access opening throughout the temporary filling materials was performed. The adaptation of CLIP and Cavit-G during adequate isolation was evaluated for the first time in the present study. CLIP was found to provide better adaptation than Cavit-G with statistically significant difference between them. This is may be attributed to Cavit having weak compressive strength, so there is a need for sufficient bulk to overcome poor strength qualities and provide an adequate seal $(24,39)$. Furthermore, Rutledge \& Montgomery (40) found that light cured temporary filling materials had higher hardness, tensile and compressive strengths than Cavit.

\section{CONCLUSIONS}

It was concluded that:

1. None of the studied materials were able to prevent microleakage, where all groups showed leakage within the study period.

2. CLIP sealed against coronal leakage better than Cavit-G when used as temporary filling materials.

3. There was a tendency for increased coronal leakage from the 3rd day to the 15th day for all groups.

4. CLIP provided better adaptation than Cavit-G on application of clamps and rubber dam. The authors declare that they have no conflicts of interest 


\section{ACKNOWLEDGEMENT}

The authors would like to express their extreme sincere gratitude and appreciation to all staff members of the Endodontic department. The first author would also like to thank his dear wife Alaa for her support throughout the study period.

\section{CONFLICT OF INTEREST}

The authors declare that they have no conflicts of interest.

\section{REFERENCES}

1. Madison S, Swanson K, Chiles SA. An evaluation of coronal microleakage in endodontically treated teeth. Part II. Sealer types. J Endod 1987; 13:109-12.

2. Cruz EV, Shigetani Y, Ishikawa K, Kota K, Iwaku M, Goodis HE. A laboratory study of coronal microleakage using four temporary restorative materials. Int Endod J. 2002; 35: 315-20.

3. Deveaux E, Hildebert P, Neut C, Boniface B, Romond C. Bacterial microleakage of Cavit, IRM, Term. Oral Surg Oral Med Oral Pathol Oral Radiol Endod 1992; 74: 634-43.

4. Jesen AL, Abbott PV, CastroSalgado J. Interim and temporary restorations of teeth during endodontic treatment. Aust Dent J 2007; 52: S83-99.

5. Vail MM, steffel CL. Preference of temporary restorations and spacers: a survey of diplomats of the American Board of Endodontists. J Endod 2006; 32: 513-5.

6. http://www.voco.com/en/products/_products/clip/.

7. Mente J, Ferk S, Dreyhaupt J, Deckert A, Legner M, Staehle HJ. Assessment of different dyes used in leakage studies. Clin Oral Investig 2010; 14: 331-8.

8. Qiong Xu, Cheung SP, Deng WJ, Ling JQ, Li WL. Sucrose as a stable tracer for quantifying endodontic leakage. J DENT SCI 2012; 7: 267-71.

9. Xu Q, Fan MW, Fan B, Cheung GSP, Hu HL. A new quantitative method using glucose for analysis of endodontic leakage. Oral Surg Oral Med Oral Pathol Oral Radiol Endod 2005; 99: 107-11.

10. Rossomando KJ, Wendt SL Jr. Thermocycling and dwell times in microleakage evaluation for bonded restorations. Dent Mater 1995; 11: 47-51.

11. $\mathrm{Xu} \mathrm{Q}$, Ling J, Cheung GSP, Hu Y. A quantitative evaluation of sealing ability of 4 obturation techniques by using a glucose leakage test. Oral Surg Oral Med Oral Pahtol Oral Radiol Endod 2007; 104: 109-13.

12. Xu Q, Fan MW, Fan B, Cheung GSP, Hu HL. A new quantitative method using glucose for analysis of endodontic leakage. Oral Surg Oral Med Oral Pathol Oral Radiol Endod 2005; 99: 107-11.

13. Kim SY, Ahn JS, Yi YA, Lee Y, Hwang JY, Seo DG. Quantitative microleakage analysis of endodontic temporary filling materials using a glucose penetration model. Acta Odontol Scand 2015; 73:137-43.

14. Cvar JF, Ryge G: criteria for the clinical evaluation of dental restorative materials. San Franscisco, Government printing office, 1971.

15. Lee YC, Yang SF, Hwang YF, Chueh LH, Chung KH.
Microleakage of endodontic temporary restorative materials. J Endod 1993; 19: 516-20.

16. Galvan RR Jr, West LA, Liewehr FR, Pashley DH. Coronal microleakage of five materials used to create an intracoronal seal in endodontically treated teeth. $\mathbf{J}$ Endod 2002; 28:59-61.

17. Fathi B, Bahcall J, Maki JS. An in vitro comparison of bacterial leakage of three common restorative materials used as an intracoronal barrier. J Endod 2007; 33:872-4.

18. Koagel SO, Mines P, Apicella M, Sweet M. In Vitro Study to Compare the Coronal Microleakage of Tempit UltraF, Tempit, IRM, and Cavit by Using the Fluid Transport Model. J Endod 2008; 34: 442- 4.

19. Ingle JI, Beveridge EE. Endodontics. 2nd ed. Philadelphia: Lea \& Febiger, 1976. 88.

20. Anderson RW, Powell BJ, Pashley DH. Microleakage of temporary restorations in complex endodontic access preparations. J Endod 1989; 15: 526-9.

21. Ciftci A, Vardarli DA, Sonmez IS. Coronal microleakage of four endodontic temporary restorative materials: An in vitro study. Oral Surg Oral Med Oral Pathol Oral Radiol Endod 2009; 108: e67-70.

22. Erdemir A, Eldeniz AU, Belli S. Effect of temporary filling materials on repair bond strengths of composite resins. J Biomed Mater Res B Appl Biomater 2008; 86B:303-9.

23. James J, John O. Burgess, James B. Summitt. Fracture resistance of amalgam coronal-radicular restorations. J Prosthet Dent 1990; 63: 607-13.

24. Webber RT, del Rio CE, Brady JM, Segall RO. Sealing quality of a temporary filling material. Oral Surg Oral Med Oral Pathol 1978; 46: 123-30.

25. Heffer R. Orthodontic band reinforced interim endodontic restorations: structural integrity and microbial penetration (MDSc thesis). Nedlands, Australia: University of Western Australia; 2007.

26. Pane ES, Palamara J. E. A, Messer HH. Stainless steel bands in endodontics: effects on cuspal flexure and fracture resistance. Int Endod J 2002; 35: 467-71.

27. Noguera AP, McDonald NJ. A Comparative in Vitro Coronal Microleakage Study of New Endodontic Restorative Materials. J Endod 1990; 16: 523-7.

28. Pommel L, Camps J. In vitro apical leakage of system B compared with other filling techniques. J Endod 2001; 27:449-51.

29. Todd MJ, Harrison JW. An evaluation of the immediate and early sealing properties of Cavit. J Endod 1979; 5: 362-7.

30. Beach CW, Calhoun JC, Bramwell JD, Hutter JW, Miller GA. clinical evaluation of bacterial leakage of endodontic temporary filling materials. J Endod 1996; 22: 459-62.

31. Ludlow M, Hermsen K. An in-vitro investigation comparing the marginal leakage of Cavit, Cavit-G, and TERM. Gen Dent 1989; 37:214-7.

32. Gilles JA, Huget EF, Stone RC. Dimensional stability of temporary restoratives. Oral Surg 1975; 40:796-800.

33. Oppenheimer S, Rosenberg PA. Effect of temperature change on the sealing properties of Cavit and Cavit G. 
Oral Surgery, Oral Medicine, Oral Pathology 1979;48, 250-3.

34. Uranga A, Blum JY, Esber S, Parahy E, Prado C. A comparative study of four coronal obturation materials in endodontic treatment. J Endod 1999; 25: 178-80.

35. Odabas ME, Tulunoglu O, Ozalp SO, Bodur H. Microleakage of different temporary filling materials in primary teeth. J Clin Pediatr Dent 2009; 34:157-60.

36. Tulunoglu O, Uçtasli MB, Ozdemir S. Coronal microleakage of temporary restorations in previously restored teeth with amalgam and composite. Oper Dent 2005; 30:331-7.

37. Lim KC. Microleakage of intermediate restorative materials. J Endod 1990; 16: 116-8.

38. Qvist V. The effect of mastication on marginal adaptation of composite restorations in vivo. J Dent Res 1983; 62:904-6.

39. Widerman FH, Eames WB, Serene TP. The physical and biologic properties of Cavit. JADA 1971; 82, 37882.

40. Rutledge RE, Montgomery S. Effect of intracanal medicaments on the sealing ability of TERM. J Endod $1990 ; 6,260-4$.

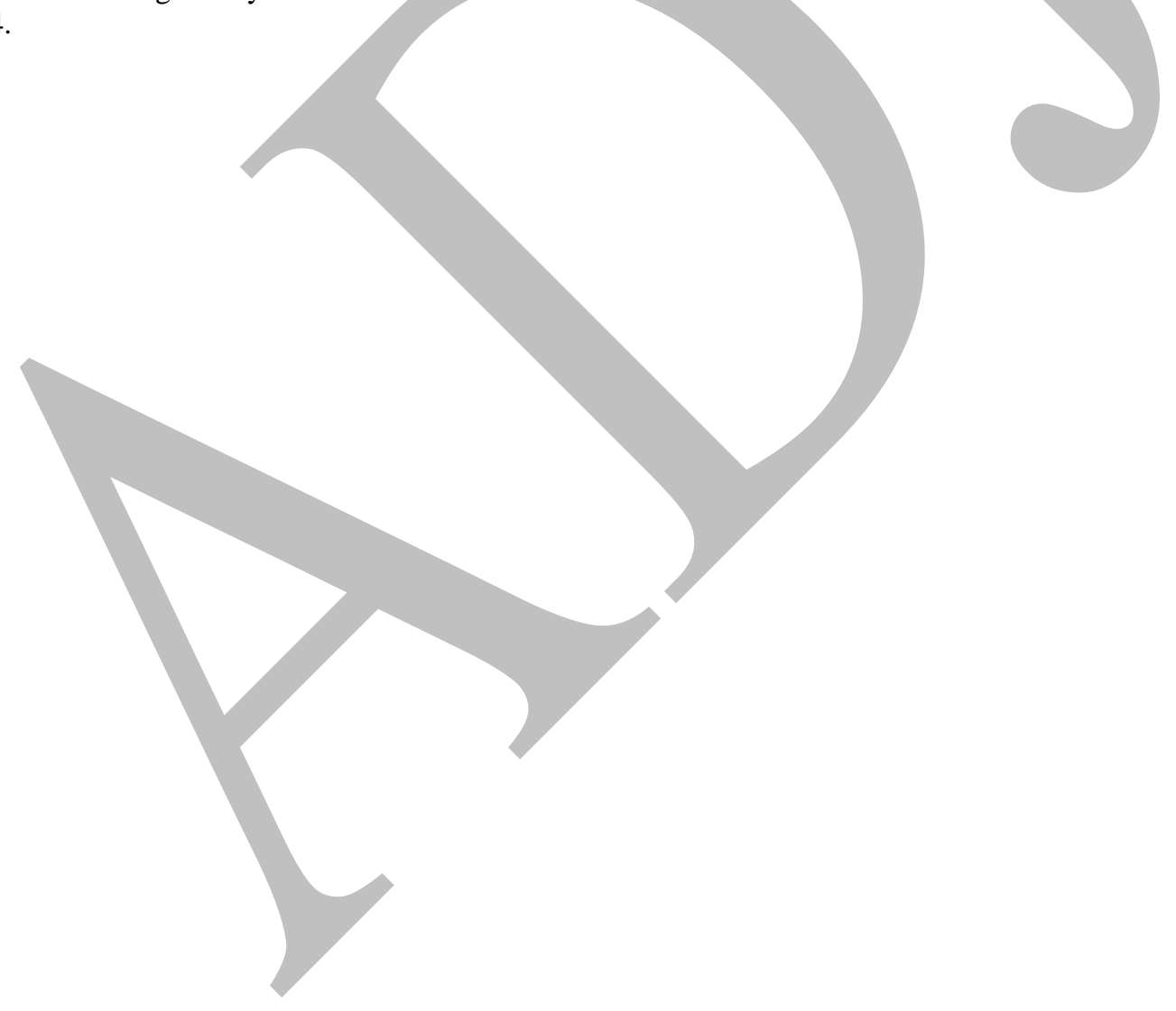

